\title{
Thijs Jansen, Gabriël van den Brink, Jos Kole: Professional Pride: A Powerful Force
}

\author{
Boom, The Hague, October 2010, 366 pp., €29.50 (paperback)
}

\author{
Marlies Honingh • Willem Trommel • Taco Brandsen
}

Published online: 10 January 2012

(C) The Author(s) 2012. This article is published with open access at Springerlink.com

Arguing that pride can be used as a powerful force to guarantee the quality of professional work, the editors of this book have brought together a rich collection of essays, interviews, narratives, and conceptual analyses about professional work in public and non-profit sectors. The book offers political, normative and scientific reflections on professionals in health care, education, safety, and social welfare. Notwithstanding their different perspectives and disciplinary backgrounds, most of the authors emphasize the benefits of dedication, the need for a certain scope of autonomy for professionals, the importance of intrinsic motivation, ownership, and the need for a proper balance between value systems within public and non-profit organizations.

Specifically noteworthy are interviews with Richard Sennett about craftsmanship and with Christopher Pollitt about blind spots in New Public Management. Both men argue that true achievement in service provision can only be realized as a result of long-term efforts. The setup of this book reflects a search for a way to actively capitalize on professional pride by answering the question whether "a consistent and practical mode of thinking can be developed which will stimulate and support professional pride and steer it in a constructive direction" (p. 15).

Each of the book's five sections is dedicated to a condition that is considered necessary for providing professionals with pride and honor-persistent commitment, operational space, courage and voice, value driven leadership, and innovation. Many empirical examples show how such virtues can be thwarted by increasingly tight organizational controls and performance measurement. A final chapter is devoted to the development of professional pride as a program for action.

\footnotetext{
M. Honingh · T. Brandsen $(\bowtie)$

Radboud University Nijmegen, Nijmegen, The Netherlands

e-mail: t.brandsen@fm.ru.nl

W. Trommel

Free University of Amsterdam, Amsterdam, The Netherlands
} 
This ideological leaning is the most debatable aspect of the book, as it is doubtful whether pride can be the antidote to organizational ills that the book's authors make it out to be, however, sympathetic the idea. The causes of the problems in the daily lives of professionals often exceed the scope of the book, as they are rooted in wider social phenomena and developments within a broader process of modernization. In her chapter in section one, Pessers emphasizes not only that institutions should combine a functional and a substantive rationality, but also that it is extremely difficult to shape the conditions in which a stable balance between these rationalities can be found. For example, the balance is currently unhinged in favor of efficiency concerns. The factors that inhibit the work of professionals are related to major social transformations and an ongoing trend of rationalization. Seen against this wider background, the notion that pride could itself be an effective antidote against de-professionalization, frustration over excessive bureaucratization, and flawed management philosophies seems overstated. It could be argued that de-professionalization is no more than a logical consequence of the rationalization process and that it is probably impossible to stop, unless society were to move in the reverse direction. At present, that would leave strategies for coping with professional issues, but no fundamental solution.

Notwithstanding its perhaps naïve emphasis on pride, the book will be valuable to readers with an interest in the changing position of professionals in current nonprofit and public organizations. The value of the book could have been greater, though, had it stepped beyond some basic limitations.

Despite the variety of theoretical disciplines involved, the scope of the volume remains theoretically limited. To begin with, the book's dominant focus on professionalism as an intra-organizational issue neglects the wider power struggles and politics that shape the professions. Professionalism is not only an organizational phenomenon, but one which is also defined at the level of professional communities and at the level of society, e.g., through the formative role of the state in closing or opening up access to professional knowledge and privileges. Remarkably, the authors do not discuss the classic critiques of professional power, as put forward by scholars like Ivan Illich and Michel Foucault. In several books, for instance on education and medicine, Illich has criticized the socio-political monopolies of professional groups with respect to defining and remedying social problems. Foucault extensively showed how the modern professions contribute to the creation of 'docile bodies' and what he labeled a politics of 'governmentality'.

Taking these criticisms seriously means that professional pride cannot be considered a value in itself. Only under certain conditions can it be a force that protects valuable practices, but this is not self-evident. Professionalism can also be an expression of organized occupational self-interest. The ambition to conceptualize professional pride in terms of a political program requires a much deeper analysis of these conditions. As it stands, it is doubtful whether the notion of 'pride' as such has the potential to foster change and to address the fundamental issues that are at stake.

Furthermore, both the pride and the professional remain underdeveloped concepts. It remains unclear whether the notion of pride is related to the nature of the profession, to specific activities or to labor conditions. And at what point does it turn from a virtue into a vice? The same goes for the concept of the professional. 
Which qualifications are necessary to be a professional? Research has shown that it is increasingly difficult to establish a clear demarcation between the professions and other occupations, an issue that the editors appear to have sidestepped.

Many of the issues addressed by the book (commitment, autonomy, control) are equally relevant to non-professionals, such as volunteers. That demonstrates both its strengths and weaknesses: the authors have made a thorough examination of contemporary issues facing the professional, but an unduly narrow focus has led them to ignore the broader relevance of their analysis and to leave some of the more interesting avenues for research unexplored.

This review is the outcome of a discussion session of the EGPA (European Group of Public Administration) Study Group on the Public Governance of Societal Sectors.

Open Access This article is distributed under the terms of the Creative Commons Attribution Noncommercial License which permits any noncommercial use, distribution, and reproduction in any medium, provided the original author(s) and source are credited. 